\title{
A critique of the ecosystem impacts of drifting and anchored FADs use by purse-seine tuna fisheries in the Western and Central Pacific Ocean
}

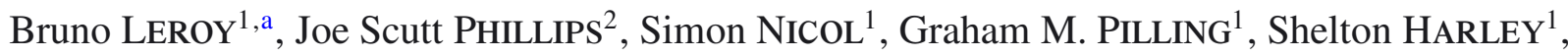 \\ Don BromHeAD $^{1}$, Simon HoYle ${ }^{1}$, Sylvain CAILlot ${ }^{1}$, Valerie Allain ${ }^{1}$ and John HAMPTON ${ }^{1}$ \\ Oceanic Fisheries Programme, Secretariat of the Pacific Community, BP D5, 98848 Noumea Cedex, New Caledonia \\ 2 Institute for Complex Systems Simulation, National Oceanography Centre, University of Southampton, UK
}

Received 22 March 2012; Accepted 12 October 2012

\begin{abstract}
In the Western and Central Pacific Ocean (WCPO), which accounts for over half of world tuna production, purse seine effort and catch on floating objects have increased significantly due to a rapid increase in the use of fixed and free-floating fish aggregation devices (FADs). FAD fishing has had an impact on the current status of the stocks of the three main target tunas in the equatorial WCPO, skipjack (Katsuwonus pelamis), yellowfin (Thunnus albacares) and bigeye (T. obesus). FADs have been shown to influence the behaviour and movement patterns of the three tuna species with the juveniles of each species occupying shallower habitats when associated with FADs. Aggregation of tunas around drifting objects increases their vulnerability to purse seine gear, particularly for juvenile and small size classes. Further to the impacts on the target stocks, the use of FADs has increased the vulnerability of other fishes to the purse seine method, including some shark and billfish species. Given the concern over FAD-related fishing effort on target and bycatch species, there is a need to understand how FAD use affects target and bycatch stocks. Science needs to better support management decisions are highlighted including the need to identify the magnitude of broader community-level affects.
\end{abstract}

Keywords: Bigeye tuna / Skipjack tuna / Yellowfin tuna / Purse seine / Fish aggregating devices / Bycatch, Pacific Ocean

\section{Introduction}

Purse-seine fishing for tuna on schools associated with floating objects has been common practice in most equatorial fisheries since the 1990s. This includes fisheries in the western and central Pacific Ocean (WCPO), which are the largest in the world in terms of both catch volume and value. Although the volume of catch from a set on floating objects is not always as high as that obtained from setting on schools that are not associated with floating objects, setting on associated schools reduces the number of sets where the catch is zero or very low (Fonteneau et al. 2000; Marsac et al. 2000). Purse seine sets on floating objects are also more fuel efficient relative to free school sets (Suuronen et al. 2012). These circumstances help create greater stability in effort and catches for purse-seine operators (Dagorn et al. 2012). The distribution of natural floating objects such as logs, or large megafauna is variable across the ocean and their presence is not always predictable even

a Corresponding author: brunol@spc.int within an area where floating objects are likely to occur in higher densities (Dagorn et al. 2012). Consequently the use of artificial fish aggregating devices (FADs) has increased, which has reduced the uncertainty of finding floating objects and generated new opportunities to fish with greater reliability in all oceanic areas.

In the WCPO the catch attributed to setting on FADs has increased substantially since purse-seining was first established in the region (Williams and Terawasi 2011). Two types of FADs have been deployed: drifting FADs (dFADs) which are used in most purse-seine tuna fisheries across the globe; and anchored FADs (aFADs) which for purse-seine tuna fishing are unique to the WCPO and deployed specifically in the archipelagic waters in the western sector (Williams and Terawasi 2011; Dagorn et al. 2012).

The current tuna catches from the WCPO are around 2.4 million metric tonnes per annum (Williams and Terawasi 2011). This represents over $55 \%$ of the global tuna catch, with a total estimated landed value exceeding USD 4 billion (FAO 2011; Williams and Terawasi 2011). The purse-seine fleet has 


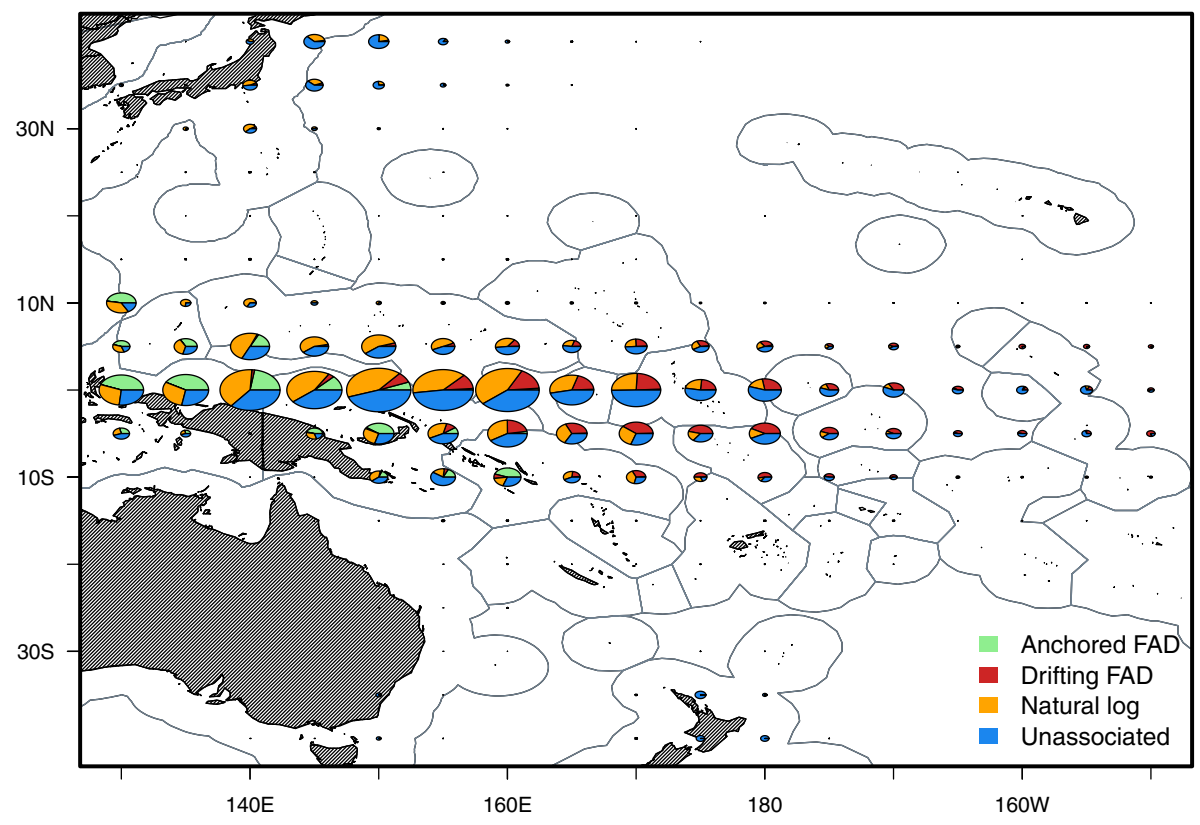

Fig. 1. Distribution and proportion of total purse seine tuna catch (metric tonnes) by set type within the Western and Central Pacific Fisheries Commission Convention Area for the period 1980 to 2010 by $5^{\circ}$ square, excluding the catch estimates for Indonesia and Philippines. The largest pie represents a total catch of 2350000 t. Source of Data: WCPFC tuna catch data.

become the dominant form of tuna fishing in the WCPO and accounts for about $75 \%$ of the total WCPO tuna catch while longline and pole-and-line fisheries each catch approximately $10 \%$ and $7 \%$ of the catch (Harley et al. 2011). The remainder is caught by troll gear and a variety of artisanal gear types mostly in eastern Indonesia and Philippines waters (Williams and Terawasi 2011). Overall, $90 \%$ of the tuna catch is taken within equatorial waters (Latitudes $15^{\circ} \mathrm{N}$ to $15^{\circ} \mathrm{S}$ ) of the Western and Central Pacific Fisheries Commission (WCPFC) Convention Area (Fig. 1). Skipjack tuna, Katsuwonus pelamis, dominates the catch of the equatorial purse-seine fishery $(70-85 \%$ of the catch), the remainder being comprised of yellowfin tuna, Thunnus albacares, (15-30\%) and a relatively small catch of bigeye tuna, T. obesus, (about 2\%). Purse seine and pole-andline vessels target younger age classes of skipjack and yellowfin tuna for canning with an incidental catch of bigeye tuna (Majkowski 2007; Williams and Terawasi 2011). A small number of longline vessels target albacore, T. alalunga, for canning with most longline vessels targeting older age classes of bigeye and yellowfin for loin and sashimi markets (Majkowski 2007; Williams and Terawasi 2011). Catches of tuna associated with FADs are approximately $27 \%$ of the total purseseine catch in the WCPO and there have been concerns raised about how the increased use of FADs may affect the sustainability of skipjack, yellowfin and bigeye tuna populations. Furthermore, many other oceanic fishes associate with floating objects (Taquet et al. 2007) and additional concerns have been raised about how FAD fishing may affect these species (Gilman 2011).

Here we critique some of the ecosystem impacts of dFAD and aFAD use in the offshore tuna purse-seine fisheries in the WCPO, using fisheries logbook and observer data; electronic and conventional tuna tagging data; and information derived from a 10 year study examining the trophic ecology of the WCPO. The critique provides an overview of the use of FADs in the WCPO; summarizes the impacts on the status and behaviour of the target stocks; indicates potential impacts on non-target species; and suggests research priorities to address key information gaps and management issues.

\section{Overview of FAD use in the Western and Central Pacific Ocean}

The total number of purse seine vessels operating in the WCPO (excluding the Japanese coastal, Indonesian and Philippines domestic fleets) has increased in the last four years to reach 280 vessels in 2010 , from a relatively stable 180 220 vessels between 1990 and 2006. Systems for collecting fishery monitoring data in Indonesia and Philippines have only recently become consistent with the wider WCPO and past estimates are uncertain. For this reason we exclude these estimates from the description of general trends and developments in the purse-seine fishery in the WCPO and report their catch and effort data separately.

Approaches for FAD deployment and FAD fishing in the WCPO have evolved through time (Fig. 2a). From the mid 1980s to 1990 similar effort was applied to setting on natural logs and unassociated schools, with very little effort on FADs. From 1990 to 1996, the total effort increased. Approximately $55 \%$ of the effort, however, was applied to unassociated schools during this period. From 1996, the total purse seine effort increased substantially with an increase in the setting on dFADs evident. In 2009 and 2010, the effort applied to FADs decreased, most probably in response to the WCPFC management measure (WCPFC 2008; 2009) that restricted the months in which FAD fishing was allowed in equatorial waters (excluding archipelagic waters). In 2010 approximately $79 \%$ 


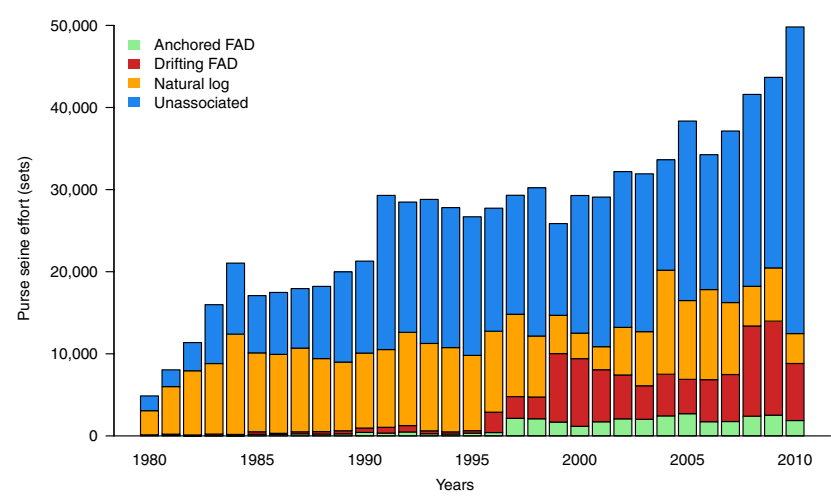

(a)

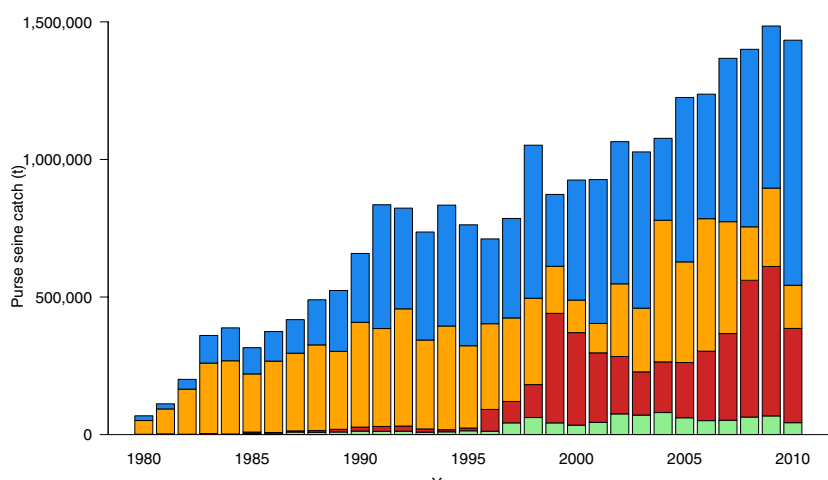

(b)

Fig. 2. (a) Total purse seine effort (sets) by school type from 1980 to 2010 within the WCPO. (b) Total purse seine tuna catch (t) by schooltype from 1980 to 2010 within the WCPO. Source of Data: WCPFC tuna catch and effort data.

of the purse seine sets were applied to unassociated schools. Catches on dFADs and logs tend to be higher than in sets on unassociated schools (Figs. 2a,b), reflecting the higher proportion of zero catch sets when setting on unassociated free schools. The domestic purse-seine fisheries in the Philippines and Indonesia have been increasingly dominated by aFAD sets since 1997 with a substantial increase in aFAD sets occurring in 2004 (Figs. 3a,b).

There is a clear spatial separation in the deployment of FADs in the WCPO (Fig. 1). aFADs are mainly deployed west of $160^{\circ} \mathrm{E}$ longitude, and mainly in the archipelagic waters of the Solomon Islands, Papua New Guinea (PNG), Indonesia and Philippines, while dFADs are more commonly deployed to the east of $160^{\circ} \mathrm{E}$. Domestic fleets operating in the Solomon Islands, PNG, Indonesia and Philippines typically comprise older and smaller vessels that lack the capacity to efficiently set on unassociated free schools. In the archipelagic areas of these EEZs, where regular aFAD maintenance is feasible using relatively small tender vessels, domestic catch and effort have been very stable since 1996 (see aFAD catch in Fig. 2b). It is more difficult and costly to use aFADs in the more remote areas east of $160^{\circ} \mathrm{E}$, for both their deployment and ongoing maintenance.

Fishing on dFADs is more variable than the fishing on aFADs. This is related to the highly mobile nature of skipjack tuna, and oceanography cycles (primarily El Niño Southern Oscillation) in the equatorial Pacific Ocean. The use of dFADs

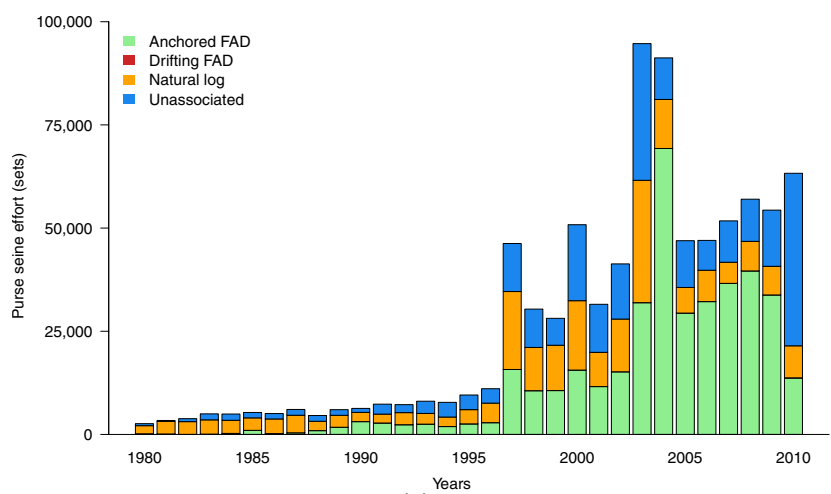

(a)

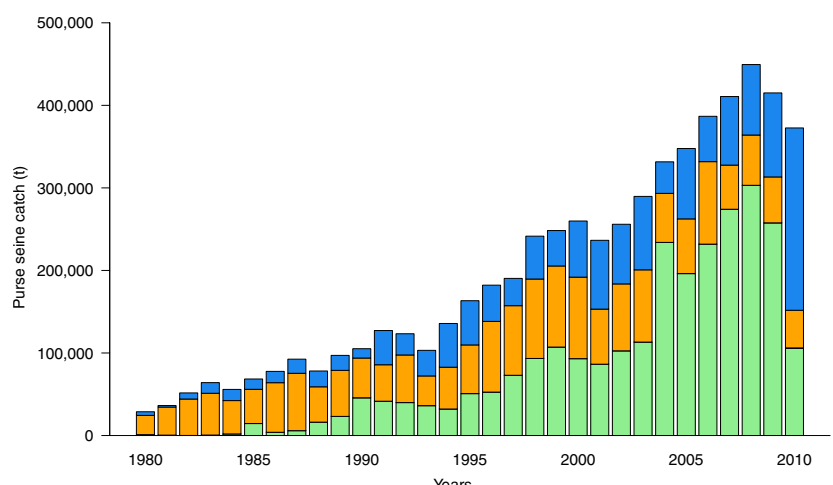

(b)

Fig. 3. (a) Total purse seine effort (sets) by school type from 1980 to 2010 within the domestic fisheries of Philippines and Indonesia. (b) Total purse seine tuna catch (t) by school-type from 1980 to 2010 within the WCPO. Source of Data: WCPFC tuna catch and effort data.

is lowest during strong El Niño events (Fig. 4) when sets on natural floating objects (e.g. logs) typically dominate. During El Niño conditions, the equatorial surface current carries warm water eastwards, and with it, logs and debris from the rivers of larger land masses in the western Pacific such as PNG, Indonesia and Solomon Islands. Floating objects tend to aggregate in productive convergence zones between currents, where a high biomass of zooplankton and zooplanktivorous species can be supported. Fishers can consequently set on logs being carried eastward in association with the shifting tropical convergence zone (e.g. the higher number of log sets in the strong and prolonged El Niño events of 1997-1998 and 2003-2004 as shown in Fig. 2a). The higher abundance of natural floating objects in the central Pacific during these periods reduces the need to deploy dFADs. During La Niña periods, the prevailing winds and equatorial current are westward, and natural logs and debris are thought to be less available in waters north or east of PNG and Solomon Islands. Fishers therefore deploy dFADs (e.g. dFAD effort is higher during the strong La Niña events in 1999-2000 and 2008-2009 as shown in Fig. 2a). Catches mirror this pattern with higher catches on dFADs during La Niña conditions (Fig. 2b).

Size compositions differ between unassociated schools and tuna associated with floating objects (Fig. 5) with associated set catches tending to be made up of smaller individuals. This is particularly notable for yellowfin tuna (Fig. 5a), where the 

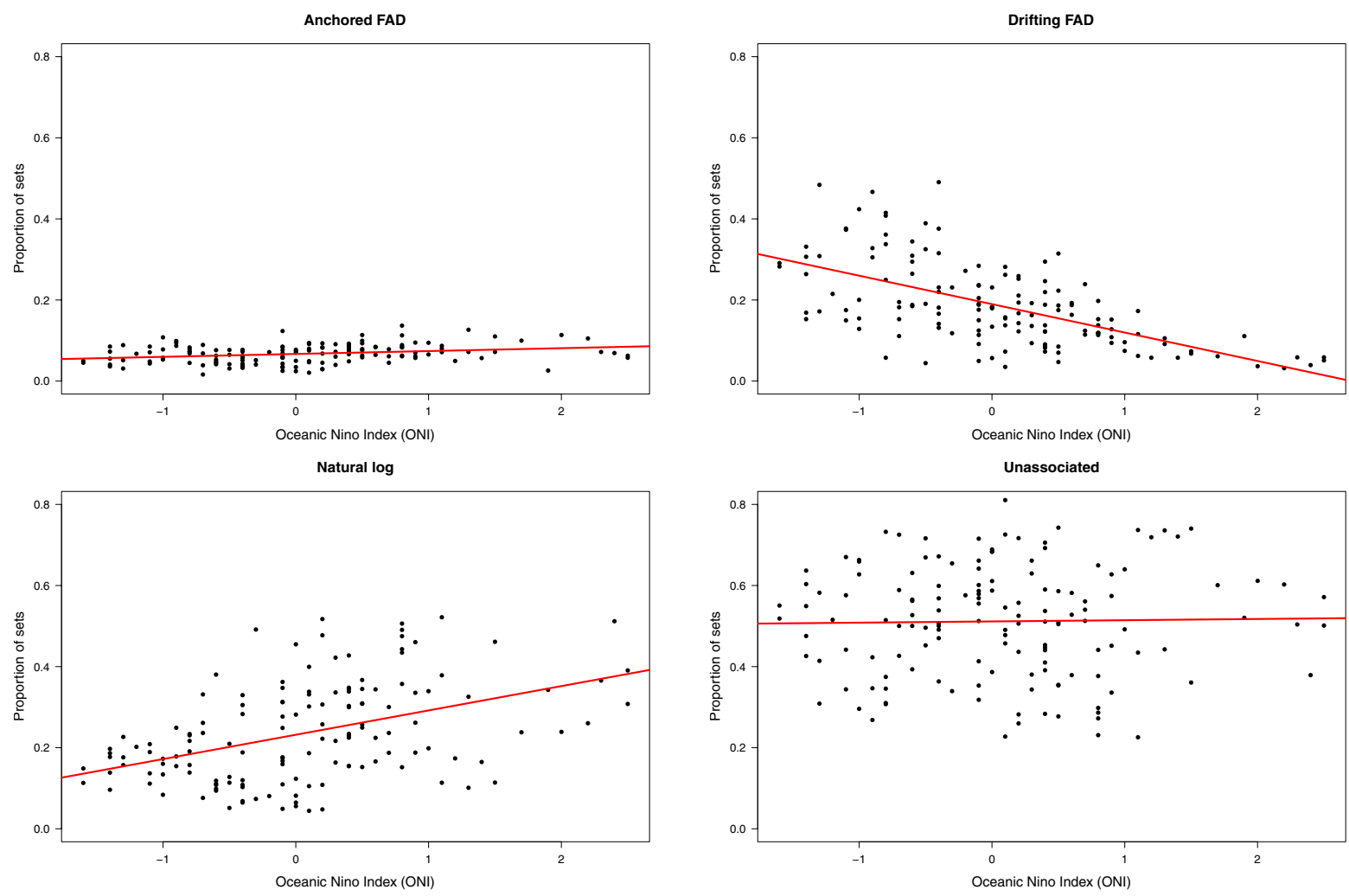

Fig. 4. Relationship between the proportion of purse seine sets by set type and the Oceanic Niño Index (ONI). The trend line is the fitted linear regression (anchored FAD $r^{2}=0.075, p<0.0009$; Drifting FAD $r^{2}=0.370, p=0.0001$; Natural $\log r^{2}=0.193, p<0.0001$; Unassociated $r^{2}=0, p=0.82$ ) Residuals satisfied the assumptions of normality for the regression. If ONI values $>0.5$ means « El Niño » and ONI $<-0.5$ means «La Niña ».

mode of fish sizes in associated sets is around $70 \mathrm{~cm}$ smaller than in unassociated sets. Fishing on FADs therefore applies proportionally more mortality per set to younger (potentially immature) fish.

\section{Impacts on the status of the target stocks}

The stock assessments undertaken for tropical tunas in the WCPO (e.g. Hoyle et al. 2011; Langley et al. 2011) incorporate catch and effort for various fisheries groups, e.g. longline, pole and line, and purse seine. Within the purse seine fishery, there is a split between fishing effort directed at associated sets (e.g. anchored and drifting FADs and logs) and unassociated sets (e.g. free schools). This allows the proportion of the overall depletion of the tuna stocks attributable to the different modes of fisheries groups to be estimated. These fishery-specific impacts are shown in Fig. 6 for yellowfin, bigeye, and skipjack tunas. The "\% impact" represents the portion of the stock at each point in time that is estimated to have been removed by fishing, relative to the total stock size that would have existed in the absence of fishing. The calculation of unexploited stock size includes an adjustment to recruitment, to acknowledge the possibility that recruitment may on average be lower at lower stock sizes.

For yellowfin tuna it is estimated that around $60 \%$ of biomass that could have existed in 2010 has been removed by fishing. Associated purse seine fishing and the domestic fisheries of Indonesia and the Philippines have contributed the most to the overall depletion. For bigeye tuna, the impact before 1980 was primarily due to longline fishing, but the advent of fishing on associated schools, and the development of the drifting FAD fisheries, have greatly increased the impact of total fishing on this stock. The FAD fisheries have reduced the estimated maximum sustainable yield for bigeye by increasing juvenile mortality (Davies et al. 2011). Should these impacts continue into the future they may impact upon the longer term viability of the longline fisheries. Unassociated modes of purse seine fishing have minimal impact on the bigeye tuna stock. Overall the present impact of fishing on bigeye tuna is estimated to be $\sim 80 \%$ which is the reason for the management concern over this stock. The overall impact of fishing on the skipjack stock is much less than for bigeye and yellowfin tuna (slightly over 40\%) and during the period 1995-2005 the impacts were split equally across the fishing modes (with the exception of longline). Since 2000 the overall impact of fishing has increased and this is being driven by associated modes of purse seine fishing.

\section{Impacts on the behaviour of the target stocks}

FADs may modify both tuna movement and condition, which has been hypothesized as a significant ecosystem impact 


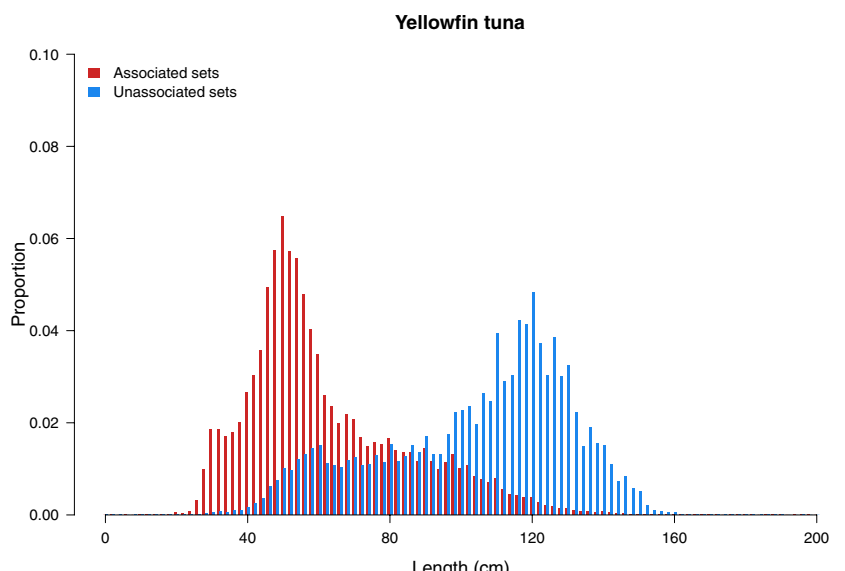

(a)

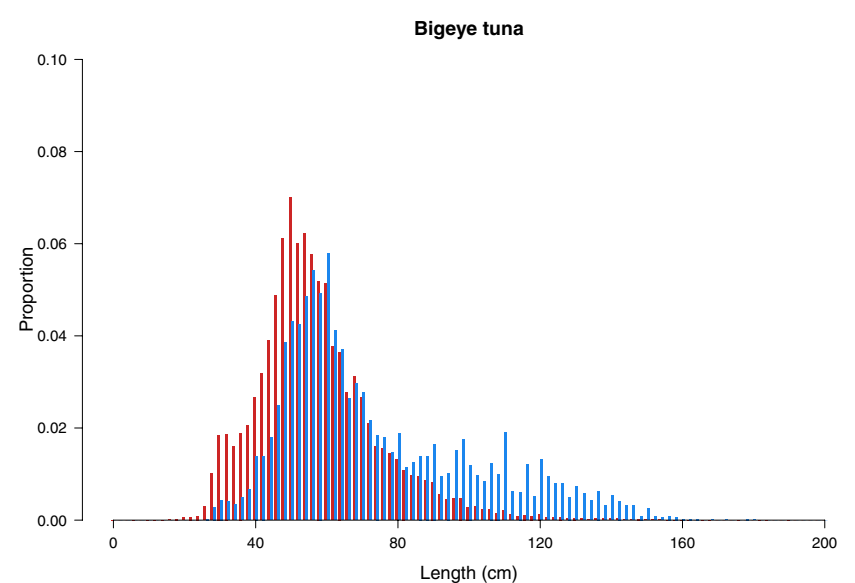

(b)

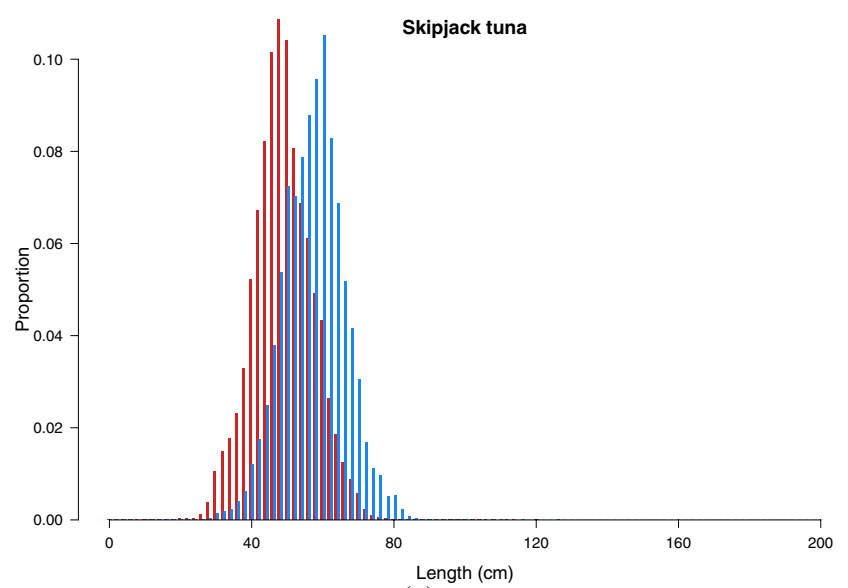

(c)

Fig. 5. Length distributions of (a) yellowfin (associated sets $n=$ 391637 , unassociated sets $n=246483$ ), (b) bigeye (associated sets $n=111791$, unassociated sets $n=8706$ ) and (c) skipjack (Associated sets $n=1655503$, unassociated sets $n=1126761$ ) sampled from associated (red) and unassociated (blue) sets. Source of Data: WCPFC tuna length data for the period 2001-2010.

(Marsac et al. 2000; Dempster and Taquet 2004; Hallier and Gaertner 2008; Dagorn et al. 2010). Their influence may result from two separate behavioural processes: attraction and

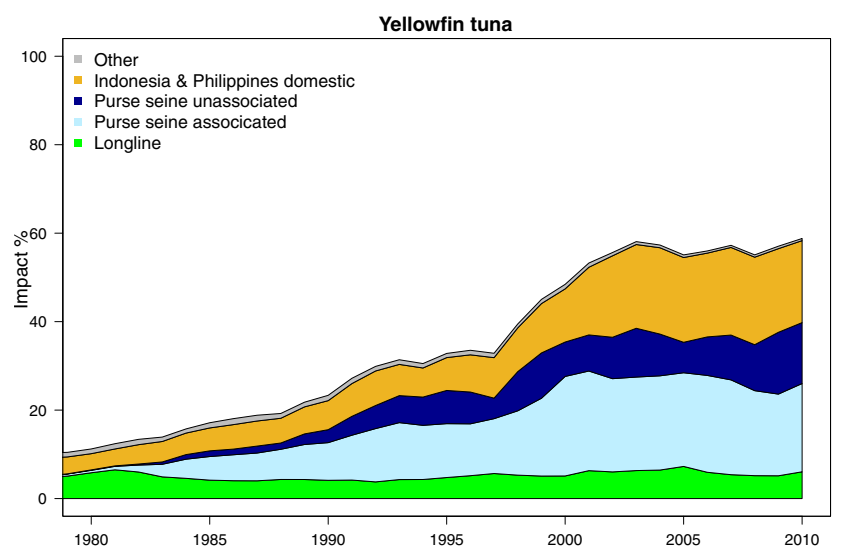

(a)

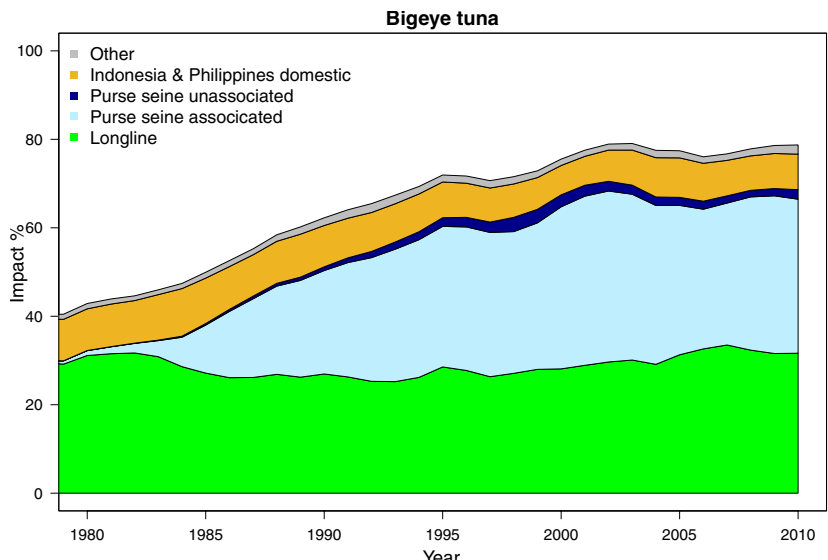

(b)

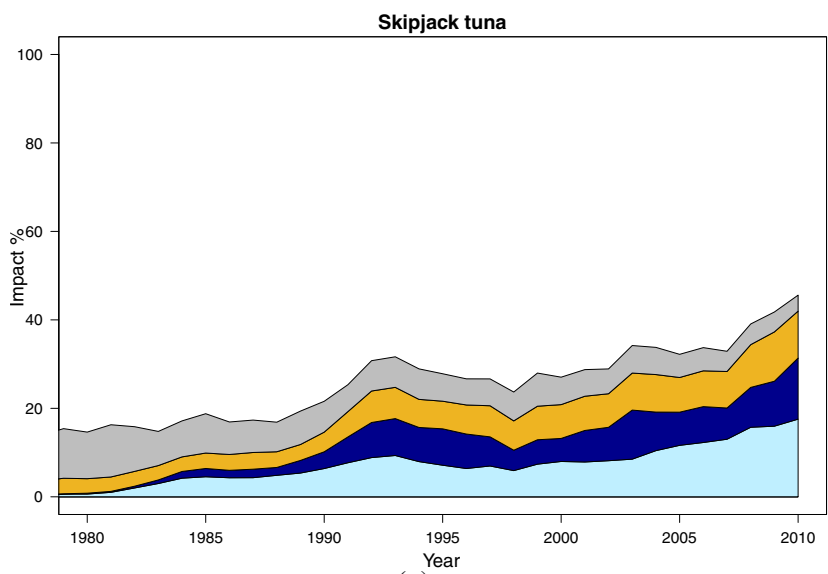

(c)

Fig. 6. Overall fishery impact plots for (a) yellowfin, (b) bigeye and (c) skipjack by fishery. Purse seine fishery impact broken down into associated and unassociated set types. Other: all other fisheries (driftnet, pole and line, troll, ringnet, handline, etc.), ID/PH: the Indonesia and Philippines fisheries, PS associated = purse seine sets associated with floating objects, PS unassociated : purse sets not associated with floating objects, Longline: all longline fisheries.

retention. The mechanisms that drive these processes are less clear. The attraction of tuna to FADs appears to be an active process (Brill et al. 1999), although this may only occur once 
fish have already encountered the assemblage through chance. Tuna appear capable of sensing and orienting movement towards FADs from around $10 \mathrm{~km}$ away, based on both detailed analysis of individual movement patterns (Girard 2004), and anecdotal fisher evidence (Moreno et al. 2007). The sensory mechanism used by pelagic fish to locate and orientate towards FADs is unknown, but is unlikely to be chemotaxic (Dempster and Kingsford 2003). It may be that low frequency sound and vibration from the anchor chains of aFADs play an important role in attracting tuna (Marsac and Cayré 1998). As both anchored and drifting FADs appear to have a similar area of influence on fish, however, noises from both the floating device itself and the aggregation of other species are plausible explanations.

When associated with FADs, tuna appear to form distinct schools (Josse et al. 1998; Schaefer and Fuller 2005; Leroy et al. 2009) that can be segregated by species, size or time of arrival (Doray et al. 2006; Moreno et al. 2007). These schools are distributed at different depths and distances from the assemblage. However, not all fish attracted to a FAD remain within its area of influence. Some tuna have been observed to actively travel towards and past a FAD without a period of residence (e.g. Brill et al. 1999), whilst many fish tagged at FADs leave shortly after capture (Holland 1996). Both attraction and retention on FADs may be size dependent, with larger sized tuna less likely to utilize FADs (Schaefer and Fuller 2010; see also Fig. 5).

The nature of vertical movement around FADs is not well understood. Schools tend to be separated, with some overlap, by depth (Bromhead et al. 2003; Leroy et al. 2009). Vertical habitat use also appears affected by FADs, with some evidence that fish inhabit shallower depths when associated with FADs (Schaefer and Fuller 2002; Leroy et al. 2009), supported by observations of bigeye ceasing their distinct daytime diving patterns (Musyl et al. 2003).

Fréon and Dagorn (2000) summarise several hypotheses explaining the behaviour of tuna around FADs. These range from potential shelter and protection provided by FADs, to a role as spatial reference points for fish. Below we examine three mechanisms likely to be important in FAD association in broad terms, alongside the observed and theoretical evidence for their plausibility in the WCPO. These are: FADs as meeting points; FADs as indicators of local productivity; and FADs affecting the prey landscape.

\subsection{FADs as meeting points}

In the pelagic realm there are very few fixed spatial points. Those that do exist, such as floating objects or seamounts, may be used by fish to increase encounter rates between isolated schools or individuals. These encounters would serve to gather fish together to optimum school sizes, and so benefit from the evolutionary advantages of schooling through increased hunting success, genetic diversity, and protection from predators (see Parrish 1991). This forms the basis for the "meeting point" hypothesis.

Tuna may follow a conspecific density-gradient to sense FADs, which could explain the "warm-up" period that is required before tuna begin to aggregate around devices for any extended residence. Simulations suggest that larger tuna school sizes may result from attraction to floating objects, although the mechanism behind the attraction process was not explicitly modelled (Dagorn and Fréon 1999). The results have been supported by some experimental evidence for other pelagic species such as bigeye shad (Selar crumenophthalmus), and to some extent Mahi-mahi (Coryphaena hippurus), suggesting that fish tend to arrive as individuals, and leave as larger aggregations (Taquet et al. 2007; Soria et al. 2009).

There is no information from the WCPO to indicate whether tuna arrive on FADs as individuals or in schools. However, WCPO-specific information is available to examine the behaviour of tuna once associated with FADs. A short term study using surgically implanted acoustic tags was undertaken to observe the behaviour of 48 skipjack, 2 juvenile bigeye and 88 juvenile yellowfin tuna in association with 3 different clusters of aFADs in the Bismarck Sea and Solomon Sea in PNG (Leroy et al. 2009). Residence times varied and variation in the departure of groups of individuals was observed in the PNG experiments, suggesting that the aggregation of tunas associated with a FAD is comprised of multiple "subschools" (Dagorn et al. 2007) in the WCPO. Several tag release cohorts of smaller sized skipjack, yellowfin and bigeye tuna $(\sim 40-50 \mathrm{~cm})$ were observed to leave the aFAD where they were tagged in closely timed groups. The occurrence of simultaneous multi-species departures from the acoustic data observations indicates the possibility of persistent multi-species schooling behaviour of similar sized tuna. This was consistent with findings of studies in other regions. Synchronized departure from FADs was also the dominant behaviour observed in the waters of the Hawaiian Islands (Klimley and Holloway, 1999; Dagorn et al. 2007). In these studies not all the tagged fish left on the same day, and typically small groups of fish left together while others remained. This is consistent with the multiple sub-school hypothesis.

\subsection{FADs as productivity indicators}

The "indicator-FAD" hypothesis assumes that, over evolutionary timescales, tuna would have evolved behavioural associations with floating $\operatorname{logs}$, branches, and drifting collections of algae. These objects could have been carried by currents over large distances, eventually aggregating at productive frontal zones and eddies. Whilst the floating objects are not themselves productive, for tuna species they may have become synonymous with rich patches of ocean. Under this assumption, man-made FADs occurring in prey-poor areas may indeed operate as ecological traps, retaining tuna in areas that they erroneously associate with high levels of prey biomass. dFADs may have more variable impacts in this regard, being capable of drifting into both more and less productive areas over relatively short timescales (Dagorn et al. 2010).

Although not direct evidence of the indicator-FAD hypothesis, there are examples of FAD-association altering the feeding and condition of fish, suggesting that the devices do affect tuna hunting strategies. Stomach contents of FAD-associated tuna examined in the Indian and Atlantic Oceans were more frequently empty than those of their free swimming counterparts, and individuals were in poorer condition (Hallier and Gaertner 2008). Differences have been found between fish associated with anchored and drifting FADs, with drifting 


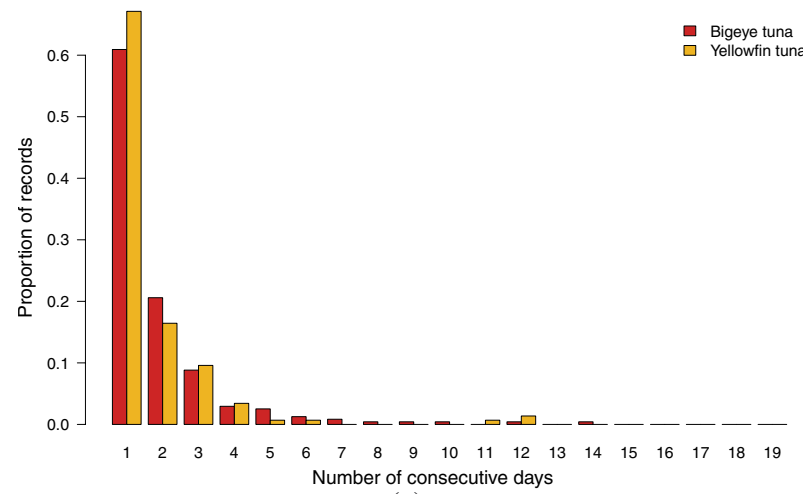

(a)

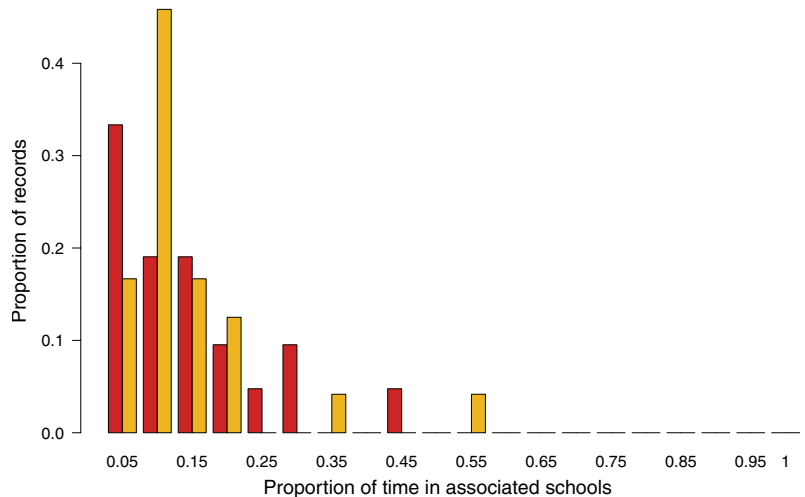

(b)

Fig. 7. (a) Frequency distribution of the continuous period of time tagged individual bigeye $(n=24)$ and yellowfin tuna $(n=21)$ were associated with floating objects. (b) Frequency distribution of the proportion of the tagged period that bigeye and yellowfin individuals $(n=45)$ displayed vertical movement behaviour consistent with associated schools.

devices associated with higher frequencies of empty stomachs (Jaquemet et al. 2011), although this impact was found to be highly location, species and age dependent.

FADs may also affect the diet of FAD-associated fish, due to the less-than-optimal searching strategy implicit in increased residence in a single area when in patchy prey landscapes. FAD-associated fish may rely more on mesopelagic prey, which migrate into nearby surface waters during the night-time. In some cases vertically migrating mesopelagic prey species are more important in the diets of FAD-associated than free-swimming tunas (Buckley and Miller 1994; Menard 2000; Graham et al. 2006). However, such effects are likely to be species specific. A WCPO study of the trophic ecology of the region over the last decade (Allain 2010) found similar proportions of surface- and deep-prey in the stomachs of bigeye caught in free schools and around FADs (approximately 10 to 15\% of deep-prey in weight for respectively 32 and 241 bigeye examined). However, for skipjack and yellowfin the pattern was opposite to the observations in other oceans; deep-prey comprised $17 \%$ of the diet for the 650 skipjack on associated sets, in comparison to $43 \%$ for the 1318 unassociated skipjack; while for yellowfin the corresponding values were $3 \%$ and $26 \%$ for 249 and 1165 fish examined respectively.

\subsection{FADs and prey landscapes}

In the open ocean, schooling tropical tunas are highly influenced by their prey environment (Dagorn et al. 2001; Kirby 2001). As many smaller fish species are known to aggregate around FADs (Taquet et al. 2007), it has been suggested that floating objects concentrate individuals of prey species on which larger fish can feed. Whilst the search for food may attract tuna to FADs, there is little evidence that sufficient prey biomass can develop at devices to support the large schools of tuna present at any one time.

Dagorn et al. (2007) studied acoustically-tagged tuna movement amongst a network of aFADs. They found that individuals rarely associated with a FAD other than that at which they were released. This was also the main observation from a study in the Bismarck Sea in PNG (Leroy et al. 2009), although some yellowfin tuna switched aFADs within the FAD cluster. Dagorn et al. (2007) concluded that at an individual or collective scale, fish may consider a FAD as representative of those in the wider area, relocating completely when conditions become unfavourable. Such movements also correspond to the optimal search behaviours already identified in tropical tuna (Humphries et al. 2010). Notable discrepancies have been seen between the continual residence times and strength of FAD-association across areas such as the Sea of Japan and Hawaiian coastal regions (Klimley and Holloway 1999; Ohta and Kakuma 2005), where prey abundance and the balance between epi- and mesopelagic species may vary regionally (Langley et al. 2008).

Simulation modelling has shown that simple attraction rules can replicate the qualitative movement patterns described by Holland (1996), based on fish losing their attraction to FADs when the absence of food caused significant hunger (Dagorn et al. 2000). Anecdotal support for this hypothesis comes from commercial fishers, for whom large scale changes in oceanic conditions were associated with tuna aggregations abandoning FADs (Moreno et al. 2007). However, an analysis of specific environmental variables did not find correlations with the end of FAD residence (Ohta and Kakuma 2005). Mean residence times of Hawaiian yellowfin and bigeye tuna at aFADs have been estimated at five to eight days, but with several continuous residence times of yellowfin up to 65 days (Dagorn et al. 2007). Similar aFAD residence times were recorded for yellowfin and bigeye tuna in Japan with longer continuous residence times of up to 55 days observed (Ohta and Kakuma 2005).

An archival tag study has been implemented in the WCPO since 2006. To date 1003 tuna (404 yellowfin, 502 bigeye, 97 skipjack) have been tagged with electronic archival tags in the equatorial zone between $130^{\circ} \mathrm{E}$ to $130^{\circ} \mathrm{W}$ longitude and 133 tags have been returned ( 49 yellowfin, 80 bigeye, 4 skipjack). Using the criteria specified in past studies (Schaefer and Fuller 2002; Schaefer et al. 2007; Leroy et al. 2009) the data from 45 recovered tags ( 21 yellowfin, 24 bigeye) that had been 


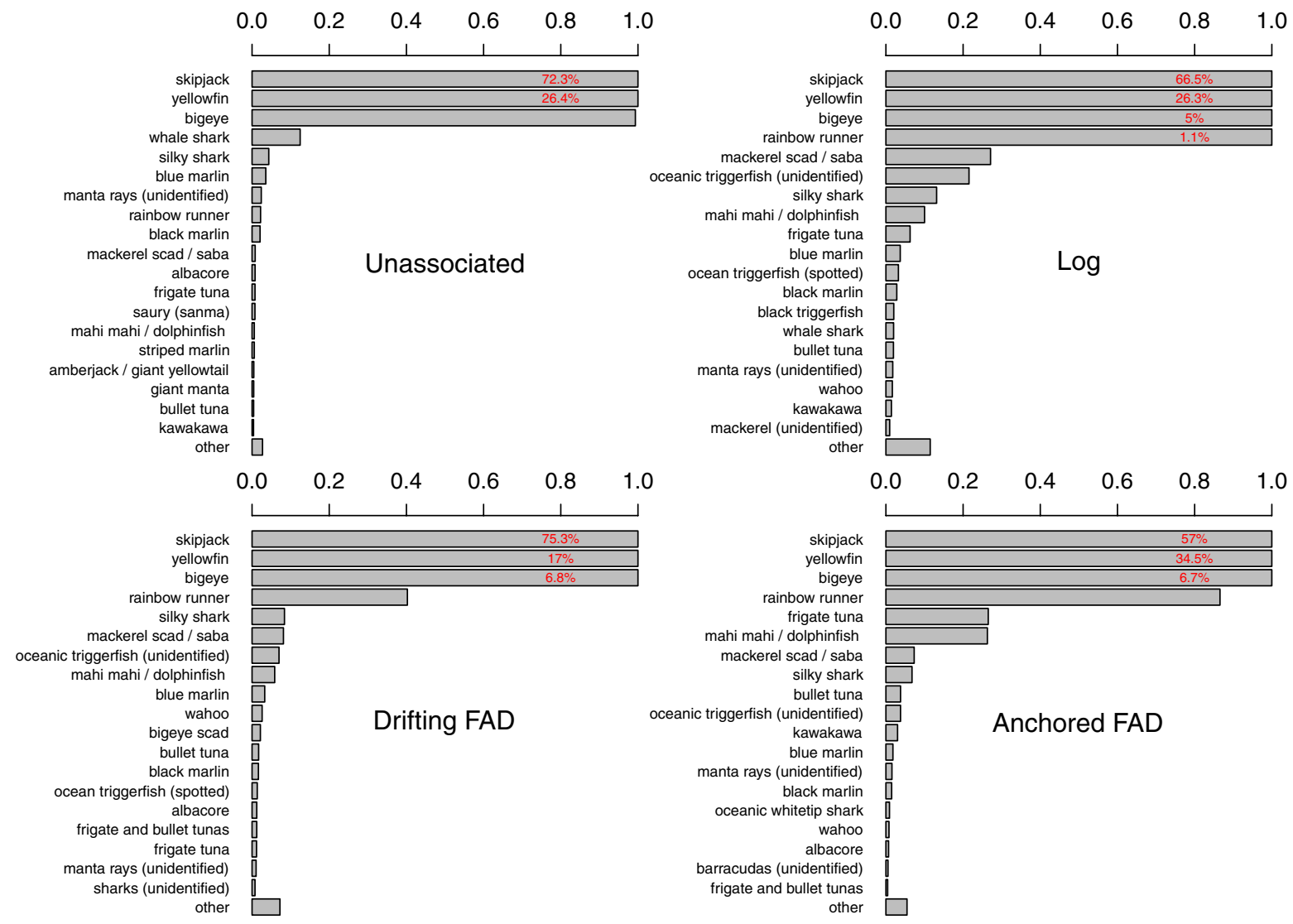

Fig. 8. Composition of purse seine catches by set type in the WCPO, based on observer data. (sample size: unassociated number of sets $\mathrm{n}($ sets $)=$ 37 894, sample weight $(\mathrm{wgt})=688000 \mathrm{t}$; Natural $\log \mathrm{n}(\mathrm{sets})=8580$, wgt $=286000 \mathrm{t}$; drifting FAD n(sets) $=11$ 126, wgt $=449000 \mathrm{t}$; anchored FAD n (sets) $=9344, \mathrm{wgt}=245000 \mathrm{t})$. Source of Data: WCPFC Observer data for the period 2001-2010.

at liberty for 30 days or more were examined. The individual daily vertical movements were examined and the behaviour classified into floating object behaviour (Schaefer and Fuller 2002; Schaefer et al. 2007) or non-FAD behaviour, providing a signal for floating object residence times. In the WCPO, tuna school associations with individual floating objects may be short-term and transient (see Fig. 7a). Most tags showed vertical behaviour consistent with floating object association for less than $15 \%$ of observations for both yellowfin and bigeye tuna (see Fig. 7b). FADs in the equatorial WCPO are far more dense and extensive than FADs in Japan and Hawaii, which may contribute to the short-term and transient nature of individual floating object association. Faced with so many floating objects, the tuna may move from one FAD-association to another rather than establishing a longer association with a single FAD. Furthermore, in the Bismarck Sea where aFADs are uniformly spaced at 9 to 10 nautical miles apart, the cumulative impact of hundreds of aFADs may entrain fish for extended periods. However this hypothesis has not been tested. In the eastern Pacific Ocean, archival tagging experiments for bigeye tuna (Schaefer and Fuller 2010) indicate that associative behaviour may be size-related with larger fish spending less time associated with floating objects. Archival tags returned from the WCPO do not suggest a similar relationship of size with residence time, but few tags have been recovered for fish at liberty for more than 180 days. The fish recovered may not have grown large enough to lose the association with floating objects as a regular part of their behaviour. Testing this hypothesis with longer deployment data if and when it is available is desirable. If longer term deployment data does not eventuate then consideration of tagging larger animals to test this hypothesis is warranted.

\section{Impacts on non-target species}

Catch composition data for the main FAD fisheries in the WCPO come from the various observer programmes operating in that region. Observer records for 41,286 sets were analysed to examine the incidence of non-target species capture. Approximately $60 \%$ of sets were on unassociated free-schools, $7 \%$ on schools associated with logs, $18 \%$ on schools associated with dFADs, $8 \%$ on schools associated with aFADs, and the remainder on schools associated with megafauna. Observers reported approximately $45 \%$ of non-associated sets and 5\% of associated sets to be unsuccessful, in that the gear was set but no or limited tuna catch resulted. The observer records included both retained and discarded catch.

Overall, catches from unassociated and associated FAD sets were dominated by tuna species $(99.6 \%$ and $98.4 \%$, respectively). Non-target species captured included marine mammals, sea turtles and some species of shark (e.g. whale 

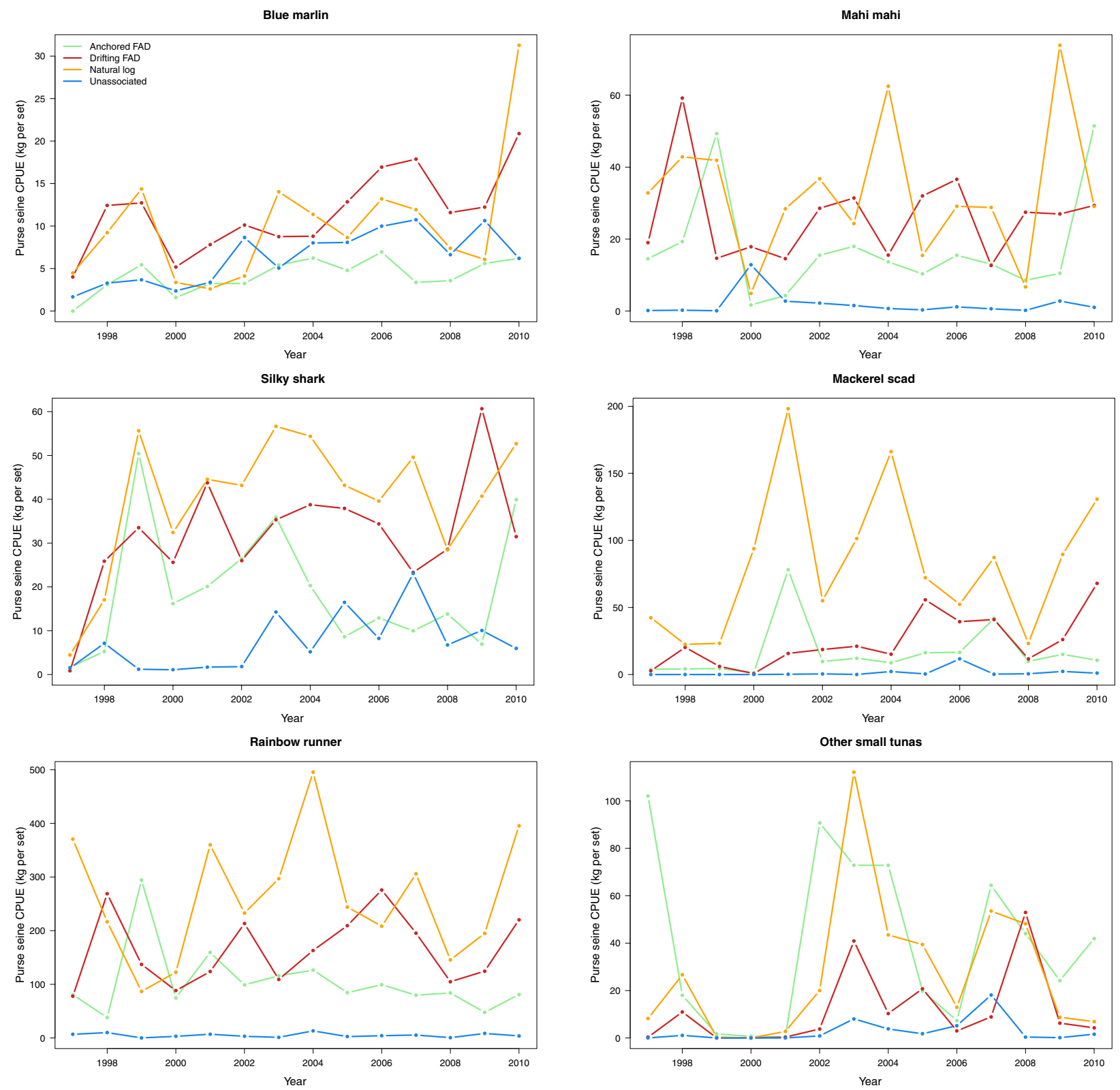

Fig. 9. Nominal catch rates of non-target species over time, by set type. Source of Data: WCPFC Observer data.

sharks in unassociated and log FAD sets (Fig. 8)). Rainbow runner (Elagatis bipinnulata), mahi mahi, silky shark (Carcharhinus falciformis), mackerel scad (Decapterus macarellus), frigate tuna (Auxis thazard), oceanic trigger fish (Canthidermis maculata), bullet (Auxis rochei) and frigate tuna and kawakawa (Euthynnus affinis) were typically observed in $>10 \%$ of observed associated sets, whereas the observation rate for non-target species in unassociated sets was typically $<5 \%$ (Fig. 8). There was sufficient data to generate nominal catch rates for blue marlin (Makaira mazara), mahi mahi, silky shark, rainbow runner, mackerel scad and a combined group of other small tunas (bullet tuna, frigate tuna, kawakawa). Catch rates were higher on floating object sets for all species except blue marlin where catch rates were equivocal between associated and unassociated sets (Fig. 9). The nominal catch rates for these species showed no strong trends in abundance (Fig. 9). The number of species recorded per set varied between set types (Fig. 10), with greater species diversity in associated sets. The median number of species recorded for non-associated sets was 1 and 3 for aFAD, dFAD and $\log$ sets.

These observations are consistent with those reported in the literature for the WCPO and other oceans. Sea turtle catch rates on FADs and logs are on average an order of magnitude higher than megafauna-associated and unassociated sets (Molony 2005; Hall 1998, 2000). Mortalities however are rare during fishing activities (FAO 2010) and more often occur when the turtle is entangled for a prolonged time and is unable to reach the surface to breathe rather than due to crushing when the net is loaded onboard (FAO 2010). Mortalities may occur due to entanglement in the submerged material attached to FADs during non-fishing periods (Gilman 2011). 
Catch rates of sharks are higher on floating object sets in comparison to unassociated sets (Molony 2005; Hall 1998, 2000; Clarke et al. 2011). Silky shark and oceanic whitetip shark (C. longimanus) are the predominant species captured by purse seine tuna fisheries (Romanov 2002; Molony 2005; Roman-Verdesoto and Orozco-Zoller 2005; Clarke et al. 2011). Preliminary results from post release survival experiments on silky shark released after being landed on-board indicates that survival rates are influenced by the time at which brailing occurred and individual condition (Hutchinson et al. 2012). Sharks released in excellent condition and those that were landed early in the fishing operations had higher post-release survival rates. In the WCPO oceanic whitetip shark are estimated to be in an overfished state however the greatest impact on the stock is attributed to bycatch from the longline fishery, with lesser impacts from target longline activities and purse seining operating in the WCPO (Rice and Harley 2012). This assessment does not distinguish between anchored and drifting FADs from other types of floating objects and does not specifically report upon the impact of FADs. The stock assessment of silky shark in the WCPO has not been accepted by the Scientific Committee of the Western and Central Pacific Fisheries Commission (WCPFC 2012) as the data used was in the assessment was considered insufficient. The historical catch rates for silky shark however follow an upward then downward trajectory for both longline and purse seine fisheries with juveniles the predominant size class caught (Clarke et al. 2011). A significant decline in median size over time was identified for both sexes in both fisheries within the core habitat of the western tropical WCPO (Clarke et al. 2011).

Floating object sets also have higher catch rates of small and juvenile bigeye and yellowfin tunas and unmarketable species and sizes of other fish species relative to unassociated sets (Fonteneau et al. 2000; Romanov 2002; Bromhead 2003; Nicol et al. 2009). Ecological risk assessments of purse-seine fisheries however indicate that the risks to populations of these other teleosts is generally lower than the risks for sea turtle, sharks and the target species (Kirby 2006; Nicol et al. 2009; Arrizabalaga et al. 2011).

\section{Future priorities}

Data and knowledge gaps currently hinder our understanding of how FADs affect oceanic ecosystems including the WCPO making it difficult to develop concise conclusions. This in part is due to the major financial cost and logistical support needed for working on offshore FADs (Dagorn et al. 2010) and consequently the sample sizes associated with such targeted research have generally been low (e.g. Schafer and Fuller 2002, 2005; Leroy et al. 2009). In the past, low fisheries observer coverage has limited alternate data acquisition programs in the WCPO. This has limited the application of stock assessment methods to evaluate the impacts of FADs on target and non-target species (Molony 2005; Kirby 2006). Developing metrics that calculate ecosystem impacts are clearly desirable and needed. Recent examples of indicator based approaches (e.g. Cury and Christensen 2005; Clarke et al. 2011; Allain et al. 2012) demonstrate advancement in this area and research to fully evaluate their utility is recommended.

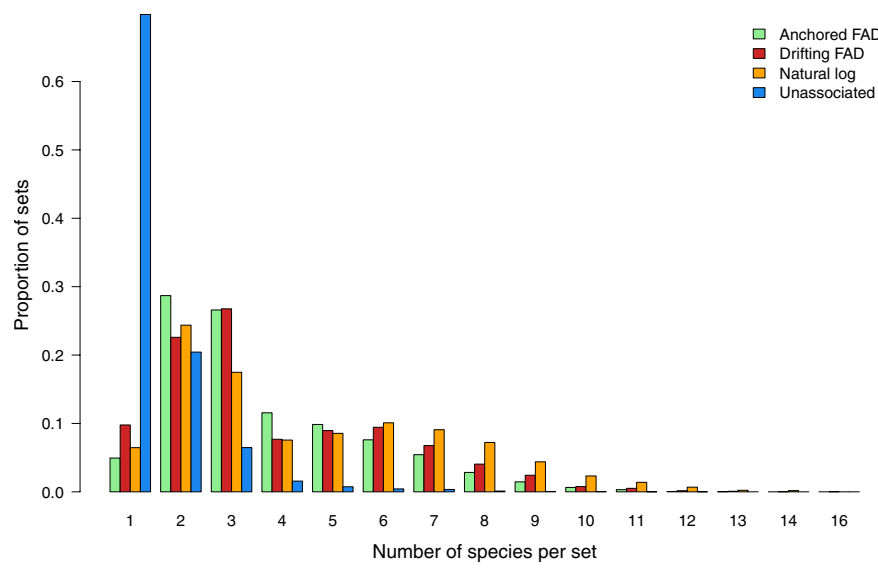

Fig. 10. Number of species recorded per purse seine set by set type. Source of Data: WCPFC Observer data for the period 2001-2010.

The WCPO observer programs are now extensive as $100 \%$ coverage on purse-seine vessels, fishing in all fleets, is now a license requirement (excluding the domestic fleets fishing in archipelagic waters) (WCPFC 2008; PNA 2010). As a result, new data collection schemes that improve our understanding of FAD fishing and its impacts in the WCPO are now feasible. An important shortcoming for data analyses is the lack of information on the number and location of FADs in use in the WCPO. A FAD registration and monitoring system would resolve this shortcoming. The Inter American Tropical Tuna Commission has recently introduced a FAD marking project for the Eastern Pacific Ocean (IATTC 2008). Under this system, each FAD is given a unique identification number which fisheries observers and/or industry record on their data forms or logbooks. This type of registration allows for improved monitoring of the number of individual FADs being fished. If the register includes the FAD design, then additional analyses can evaluate how FAD features influence catches (e.g. the type, amount and depth of submerged structure). Modern dFADs are also typically equipped with remote tracking capacity to allow fishing vessels to locate them efficiently. Access to this data would allow information on dFAD attraction and oceanography and drifting speeds to be evaluated. These types of analyses would help fisheries managers and industry to develop policies to ensure fishery sustainability and reduce ecosystem impacts.

Improved fisheries observer coverage in the WCPO will also permit greater use of spill sampling to quantify species composition of purse-seine catches. To date, the most common species composition sampling methods in the WCPO have been grab sampling and port sampling. In grab sampling, the observer randomly takes fish to measure, but recent analyses have demonstrated that the selection of fish for measurement is rarely random (Lawson 2010). Similarly, recent analyses of port sampling data have identified that the fish landed may not always be representative of the tuna catch due to some discarding and/or sorting of fish prior to unloading at port. Spill sampling removes these biases by removing the human element from the selection of fish to be identified and measured by the fisheries observer during the fishing operation. The fish are brailed from the purse-seine net, and before entering the holding wells are filtered through a sampling bin. Those fish retained in the bucket are measured for species composition 
and length (Lawson 2010). More use of this method would give more reliable estimates of catch by species. The catch of juvenile bigeye tuna is a particular management concern in the WCPO as the stock is considered fully exploited. Reliable inference for estimating the total catch of juvenile bigeye will be increasingly important to assess the impact that FAD fishing is having on this stock.

Tuna behaviour around FADs has been observed for many years, but the factors driving the observed behaviour patterns remain unclear. We have briefly reviewed the processes occurring, but there is still insufficient evidence to confirm specific hypotheses. However, these mechanisms are not mutually exclusive, and the evidence that does exist suggests that all may operate under certain circumstances. The prey landscape is clearly important for tuna, but the ways in which FADs interact with the biotic components of tuna environmental preferences, through prey concentration, increased feeding on juvenile conspecifics, or incorrect habitat utilisation, need further investigation. Evidently, this will require further research into not only tuna foraging, but also the effect of FADs on the behaviour of other important species in the pelagic ecosystem. Opportunities to apply double tagging using acoustic and archival tags on larger individuals to correlate behaviour of these animals around FADs with acoustic listening stations (as described in Leroy et al. 2009) would assist with confirming vertical behaviours around FADs rather than relying solely on inference from dive analyses (Schaefer and Fuller 2002, 2005). A particularly important aspect for future investigation will also be how FAD density affects tuna behaviour and whether "ecological trap" hypotheses (Marsac et al. 2000; Hallier and Gaertner 2008) are valid for the WCPO. The recent review of the global impacts of FADs on tuna highlighted the need for hypotheses associated with FAD density to be tested in multiple oceans (Dagorn et al. 2012). Combined with improved understanding of the impacts of FADs on individual and stock-wide biology, this knowledge will inform management decisions on the impacts of FADs within the WCPO.

Acknowledgements. We acknowledge the important work done by the national observer programs of the member countries of the Secretariat of the Pacific Community. This work is part of the Pacific Islands Oceanic Fisheries Management Project supported by Global Environment Facility, the New Zealand Agency for International Development project "Pacific Tuna Tagging Project Phase 2 (2008-2012), the 9th European Union Development Fund project "SCIFISH". 10th European Union Development Fund project "SCICOFISH", and the Republic of Korea who have contributed financial support to the Phase 2 of the "Pacific Tuna tagging Project". The implementation of the tuna tagging experiments described in this manuscript has been undertaken in partnership with the National Fisheries Authority, Papua New Guinea.

\section{References}

Allain V., 2010, Trophic structure of the pelagic ecosystems of the western and central Pacific Ocean. WCPFC-SC6-2010/EB-IP-10.

Allain V., Griffiths S. P., Polovina J. Nicol S., 2012, WCPO ecosystem indicator trends and results from ecopath simulations. WCPFCSC8-2012/EB-IP-12.
Arrizabalaga H., de Bruyn P., Diaz G. A., Murua H., Chavance P., de Molina A. D., Gaertner D., Ariz J., Ruiz J., Kell L. T., 2011, Productivity and susceptibility analysis for species caught in Atlantic tuna fisheries. Aquat. Living Resour. 24, 1-12.

Brill R.W., Block B.A., Boggs C.H., Bigelow K.A., Freund E.V., Marcinek D.J., 1999, Horizontal movements and depth distribution of large adult yellowfin tuna (Thunnus albacares) near the Hawaiian Islands, recorded using ultrasonic telemetry: implications for the physiological ecology of pelagic fishes. Mar. Biol. 133, 395-408.

Bromhead D., Foster J., Attard R., Findlay J., Kalish J., 2003, A review of the impact of fish aggregating devices (FADs) on tuna fisheries. Bureau of Rural Sciences, Canberra.

Buckley T., Miller B., 1994, Feeding habits of yellowfin tuna associated with fish aggregation devices in American Samoa. Bull. Mar. Sci. 55, 445-459.

Clarke S., Harley S., Hoyle S., Rice J., 2011, An indicator-based analysis of key shark species based on data held by SPC-OFP WCPFC-SC7-2011/EB-WP-01.

Cury P.A., Christensen V., 2005, Quantitative ecosystem indicators for fisheries management, Introduction. ICES. J. Mar. Sci. 62, 307-310.

Dagorn L., Fréon P., 1999, Tropical tuna associated with floating objects: a simulation study of the meeting point hypothesis. Can. J. Fish. Aquat. Sci. 56, 984-993.

Dagorn L., Menczer F., Bach P., Olson R.J., 2000, Co-evolution of movement behaviours by tropical pelagic predatory fishes in response to prey environment: a simulation model. Ecol. Mod. 134, 325-341.

Dagorn L., Bertrand A., Bach P., Petit M., Josse E., 2001, Improving our understanding of tropical tuna movements from small to large scales. In: Electronic tagging and tracking in marine fisheries: Proc. Symp. Tagging and Tracking Marine Fish with Electronic Devices, USA, Kluwer Academic Publ., University of Hawaii.

Dagorn L., Holland K. N., Itano D. G., 2007, Behavior of yellowfin (Thunnus albacares) and bigeye (T. obesus) tuna in a network of fish aggregating devices (FADs). Mar. Biol. 151, 595-606.

Dagorn L., Holland K.N., Filmalter J., 2010, Are drifting FADs essential for testing the ecological trap hypothesis? Fish. Res. 106, 60-63.

Dagorn L., Holland K. N., Restrepo V., Moreno G., 2012, Is it good or bad to fish with FADs? What are the real impacts of the use of drifting FADs on pelagic marine ecosystems? Fish. Fish. DOI: 10.1111/j. 1467-2979.2012.00478.x.

Davies N., Hoyle S., Harley S., Langley A., Kleiber P., Hampton J., 2011, Stock assessment of bigeye tuna in the Western and Central Pacific Ocean. WCPFC-SC7-2011/SA-WP-02.

Dempster T., Kingsford M., 2003, Homing of pelagic fish to fish aggregation devices (FADs): the role of sensory cues. Mar. Ecol. Prog. Ser. 258, 213-222.

Dempster T., Taquet M., 2004, Fish aggregation device (FAD) research: gaps in current knowledge and future directions for ecological studies. Rev. Fish Biol. Fish. 14, 21-42.

Doray M., Josse E., Gervain P., Reynal L., Chantrel J., 2006, Acoustic characterization of pelagic fish aggregations around moored fish aggregating devices in Martinique (Lesser Antilles). Fish. Res. $82,162-175$.

FAO, Food and Agriculture Organization of the United Nations, 2010, Guidelines to reduce sea turtle mortality in fishing operations. Fisheries and Aquaculture Department, FAO, Rome. 
FAO, Food and Agriculture Organization of the United Nations, 2011, Fisheries and Aquaculture Department, Atlas of tuna and billfish catches, http://www.fao.org/fishery/statistics/tuna-atlas/query/en, accessed 25 November 2011.

Fonteneau A., Pallares P., Pianet R., 2000, A worldwide review of purse seine fisheries on FADs. In: Pêche thonière et dispositifs de concentration de poisons, Actes Coll.-IFREMER 28, pp. 15-35.

Fréon P., Dagorn L., 2000, Review of fish associative behaviour: toward a generalisation of the meeting point hypothesis. Rev. Fish Biol. Fish. 10, 183-207.

Gilman, E., 2011, Bycatch governance and best practice mitigation technology in global tuna fisheries. Mar. Policy 35, 590-609.

Girard C., 2004, FAD: Fish Aggregating Device or Fish Attracting Device? A new analysis of yellowfin tuna movements around floating objects. Anim. Behav. 67, 319-326.

Graham B.S., Grubbs D., Holland K., Popp B.N., 2006, A rapid ontogenetic shift in the diet of juvenile yellowfin tuna from Hawaii. Mar. Biol. 150, 647-658.

Hall M., 1998, An ecological view of the tuna-dolphin problem: impacts and trade-offs. Rev. Fish Biol. Fish. 8, 1-34.

Hall M.A., Alverson D., Metuzals I., 2000, By-catch: problems and solutions. Mar. Pollut. Bull. 41, 204-219.

Hallier J., Gaertner D., 2008, Drifting fish aggregation devices could act as an ecological trap for tropical tuna species. Mar. Ecol. Prog. Ser. 353, 255-264.

Harley S.J., Williams P., Nicol S., Hampton J., 2011, The western and central Pacific tuna fishery: 2010 overview and status of stocks. Tuna Fisheries Assessment Rep. 11. Noumea, Secretariat of the Pacific Community.

Holland K.N., 1996, Biological aspects of the association of tunas with FADs. SPC FAD (Fish Aggregating Device). Inf. Bull. 2, 2-7.

Hoyle S., Kleiber P., Davies N., Langley A., Hampton J., 2011, Stock assessment of skipjack tuna in the western and central Pacific Ocean, WCPFC-SC7-2011/SA-WP-04.

Humphries N.E., Queiroz N., Dyer J. R.M., Pade N.G., Musyl M.K., Schaefer K.M., Fuller D.W., Brunnschweiler J.M., Doyle T.K., Houghton J.D. R., Hays G.C., Jones C.S., Noble L.R., Wearmouth V.J., Southall E.J., Sims D.W., 2010, Environmental context explains Levy and Brownian movement patterns of marine predators. Nature 465, 1066-1069.

Hutchinson M., Itano D., Muir J., Leroy B., Holland K., 2012, The post-release condition of FAD associated silky sharks (Carcharhinus falciformis) caught in tuna purse seine gear. WCPFC-SC8-2012/ EB-WP-12 Rev 1.

IATTC, Inter American Tropical Tuna Commission, 2008, FAD related Research WCPFC-SC4-2008/FT-IP-3.

Jaquemet S., Potier M., Ménard F., 2011, Do drifting and anchored Fish Aggregating Devices (FADs) similarly influence tuna feeding habits? A case study from the western Indian Ocean. Fish. Res. 107, 283-290.

Josse E., Bach P., Dagorn L., 1998, Simultaneous observations of tuna movements and their prey by sonic tracking and acoustic surveys. Hydrobiologia 371, 61-69.

Kirby D., 2001, On the integrated study of tuna behaviour and spatial dynamics: tagging and modeling as complementary tools. In: Electronic tagging and tracking in marine fisheries. Dordrecht, Kluwer Academic Publishers, pp. 407-420.

Kirby D.S., 2006, Ecological risk assessment for species caught in WCPO tuna fisheries: inherent risk as determined by productivity-susceptibility analysis. WCPFC-SC2-2006/EB-WP-1.
Klimley A., Holloway C., 1999, School fidelity and homing synchronicity of yellowfin tuna, Thunnus albacares. Mar. Biol. 133, 307-317.

Langley A., Hoyle S., Hampton J., 2011, Stock assessment of yellowfin tuna in the western and central Pacific Ocean, WCPFCSC7-2011/SA- WP-03.

Langley A., Williams P., Hampton J., 2008, The Western and Central Pacific tuna fishery: 2006 overview and status of stocks. Tuna Fisheries Assessment. Technical Report 8, Secretariat of the Pacific Community, Noumea, New Caledonia.

Lawson T., 2010, Update on the estimation of selectivity bias based on paired spill and grab samples collected by observers on purse seiners in the Western and Central Pacific Ocean WCPFC-SC62010/ST-WP-2.

Leroy B., Itano D.G., Usu T., Nicol S.J., Holland K.N., Hampton J., 2009, Vertical Behavior and the Observation of FAD Effects on tropical tuna in the warm-pool of the Western Pacific Ocean. In: Tagging and tracking of marine animals with electronic Devices. Springer, Part 1, pp. 161-179.

Majkowski J., 2007, Global fishery resources of tuna and tunalike species. Food and Agriculture Organization of the United Nations, Rome. FAO Fish. Techn. Pap. 483.

Marsac F., Cayré P., 1998, Telemetry applies to behaviour of yellowfin tuna (Thunnus albacares) movements in a network of fish aggregating devices. Hydrobiologia 371, 155-171.

Marsac F, Fonteneau A, Ménard F., 2000, Drifting FADs used in tuna fisheries: an ecological trap? In: Pêche thonière et dispositifs de concentration de poisons, Actes Colloques-IFREMER 28, pp. 537-552.

Menard F., 2000, Exploitation of small tunas by a purse-seine fishery with fish aggregating devices and their feeding ecology in an eastern tropical Atlantic ecosystem. ICES J. Mar. Sci. 57, 525-530.

Molony B., 2005, Estimates of the mortality of non-target species with an initial focus on seabirds, turtles and sharks. WCPFCSC1-2005/EB-WP-1.

Moreno G., Dagorn L., Sancho G., Itano D., 2007, Fish behaviour from fishers' knowledge: the case study of tropical tuna around drifting fish aggregating devices (DFADs). Can. J. Fish. Aquat. Sci. 64, 1517-1528.

Musyl M.K., Brill R.W., Boggs C.H., Curran D.S., Kazama T.K., Seki M.P., 2003, Vertical movements of bigeye tuna (Thunnus obesus) associated with islands, buoys, and seamounts near the main Hawaiian Islands from archival tagging data. Fish. Oceanogr. 12, 152-169.

Nicol S., Lawson T., Briand K., Kirby D., Molony B., Bromhead D., Williams P., Schneiter E., Ludwig L., John Hampton J., 2009, Characterisation of the tuna purse seine fishery in Papua New Guinea. Australian Centre for International Agricultural Research, Canberra.

Ohta I., Kakuma S., 2005, Periodic behavior and residence time of yellowfin and bigeye tuna associated with fish aggregating devices around Okinawa Islands, as identified with automated listening stations. Mar. Biol. 146, 581-594.

Parrish J., 1991, Do predators 'shape' fish schools: interactions between predators and their schooling prey. Neth. J. Zool. 42, 358-370.

PNA, Parties to the Nauru Agreement, 2010, A third arrangement implementing the Nauru Agreement setting fourth additional terms and conditions of access to the fisheries zones of the parties.

Rice J., Harley S., 2012, Stock assessment of oceanic whitetip sharks in the western and central Pacific Ocean. WCPFC-SC8-2012/SAWP-06. 
Romanov E., 2002, Bycatch in the Tuna Purse-Seine fisheries of the Western Indian Ocean. Fish. Bull. 100, 90-105.

Roman-Verdesoto M, Orozco-Zoller M., 2005, Bycatches of sharks in the tuna purse-seine fishery of the eastern Pacific Ocean reported by observers of the Inter-American Tropical Tuna Commission, 1993-2004. Data Rep. 11. Inter-Am. Trop. Tuna Comm., La Jolla, CA.

Schaefer K.M., Fuller D.W., 2002, Movements, behavior, and habitat selection of bigeye tuna (Thunnus obesus) in the eastern equatorial pacific, ascertained through archival tags. Fish. Bull. 100, 765-788.

Schaefer K.M., Fuller D.W., 2005, Behavior of bigeye (Thunnus obesus) and skipjack (Katsuwonus pelamis) tunas within aggregations associated with floating objects in the equatorial eastern Pacific. Mar. Biol. 146, 781-792.

Schaefer K.M., Fuller D.W., Block B.A., 2007, Movements, behavior, and habitat utilization of yellowfin tuna (Thunnus albacares) in the northeastern Pacific Ocean, ascertained through archival tag data. Mar. Biol. 152, 502-525.

Schaefer K.M., Fuller D.W., 2010, Vertical movements, behavior, and habitat of bigeye tuna (Thunnus obesus) in the equatorial eastern Pacific Ocean, ascertained from archival tag data. Mar. Biol. 157, 2625-2642.

Soria M., Dagorn L., Potin G., Fréon P., 2009, First field-based experiment supporting the meeting point hypothesis for schooling in pelagic fish. Anim. Behav. 78, 1441-1446.
Suuronen P., Chopin F; Glass C; Lokkeborg S; Matsushita Y; Queirolo D; Rihan D., 2012, Low impact and fuel efficient fishing-Looking beyond the horizon. Fish. Res. 119, 135-146.

Taquet M., Dagorn L., Gaertner J.-C., Girard C., Aumerruddy R., Sancho G., ,Itano D., 2007, Behaviour of dolphinfish (Coryphaena hippurus) around drifting FADs as observed from automated acoustic receivers. Aquat. Living Resour. 20, 323-330.

WCPFC, The Commission for the Conservation and Management of Highly Migratory Fish Stocks in the Western and Central Pacific Ocean, 2008, Conservation and management measure for bigeye and yellowfin tuna in the western and central Pacific Ocean, Conservation and Management Measure 2008-01 WCPFC5.

WCPFC, The Commission for the conservation and management of highly migratory fish stocks in the Western and Central Pacific Ocean, 2009, Conservation and management measure on the application of high seas FAD closures and catch retention, Conservation and Management Measure 2009-02 WCPFC6.

WCPFC, The Commission for the conservation and management of highly migratory fish stocks in the Western and Central Pacific Ocean, 2012, 7th regular session of the Scientific Committee: summary report with executive summary (8 Oct 2012). Western and Central Pacific Fisheries Commission, Kolonia, Pohnpei Western and Central Pacific Fisheries Commission.

Williams P., Terawasi P., 2011, Overview of tuna fisheries in the western and central Pacific Ocean, including economic conditions 2010. WCPFC-SC7-2011/GN-WP-01. 